\title{
Studi Automatic Picking Waktu Tiba Gelombang P dan S dengan Menggunakan Spektogram pada Obspy Python
}

\author{
Indriati Retno Palupi ${ }^{(a)}$ dan Wiji Raharjo ${ }^{(b)}$ \\ Jurusan Teknik Geofisika,Universitas Pembangunan Nasional Veteran, Yogyakarta, Indonesia 55283 \\ Email : ${ }^{(a)}$ inder13101986@ gmail.com, ${ }^{(b)}$ wiji.raharjo@upnyk.ac.id
}

Diterima (31 Desember 2019), Direvisi (28 Januari 2020)

\begin{abstract}
One of important thing in locating hypocenter process is determine $P$ and $S$ arrival time of the seismogram. Beside that, frequency analysis by FFT method is needed to know the character of the seismogram, like dominant frequency. For further analysis, FFT method can be a good tools in determine $P$ and $S$ wave arrival time in the spectogram form. This process is called automatic picking.
\end{abstract}

Keywords: Seismogram, P and S wave arrival time, hypocenter, FFT and Spectogram.

Abstrak. Salah satu parameter penting dalam menentukan posisi hiposenter adalah dengan menentukan waktu tiba gelombang $\mathrm{P}$ dan $\mathrm{S}$ dari rekaman gelombang gempa bumi (seismogram). Analisa mengenai frekuensi terhadap seismogram menggunakan teknik Fast Fourier Transform (FFT) menjadi hal yang penting. Selain dapat digunakan untuk mengetahui besarnya frekuensi dominan dari seismogram, analisa FFT lanjut dalam bentuk spektogram dapat membantu dalam menentukan waktu tiba gelombang $\mathrm{P}$ dan $\mathrm{S}$ secara otomatis atau dikenal dengan automatic picking.

Kata kunci: Seismogram, waktu tiba gelombang P dan S, hiposenter, FFT, Spektogram.

\section{PENDAHULUAN}

Indoneisa merupakan salah satu negara yang rawan akan potensi bencana gempa bumi karena letaknya yang berada pada perbatasan tiga lempeng besar yaitu Australia, Eurasia dan Pasifik (Gambar 1)[1]. Akibat dari adanya arus konveksi pada mantel bumi, mengakibatkan lempenglempeng tersebut bergerak dan menghasilkan sumber-sumber gempa bumi seperti zona subduksi dan patahan.

Gempa bumi mearupakan bencana alam yang sampai saat ini belum dapat diprediksi kapan waktu terjadinya Pendekatan yang dilakukan sampai saat ini untuk waktu terjadinya gempa adalah dengan menggunakan metode statistik. Selain itu, kendala yang dialami dalam mitigasi bencana gempa bumi adalah penentuan lokasi pusat gempa bumi (hiposenter). Padahal informasi tersebut sangat penting dalam menunjang proses mitigasi bencana terutama dalam hal waktu evakuasi masyarakat yang tinggal di sekitar lokasi bencana gempa bumi.

Salah satu parameter penting dalam menghitung hiposenter adalah penentuan waktu tiba gelombang $\mathrm{P}$ (primer) dan gelombang $S$ (sekunder) dari rekaman gelombang gempa bumi (seismogram). Metode yang biasa digunakan yaitu dengan cara manual dinilai kurang efektif mengingat 
keefektifan dan kecepatan waktu dalam proses perhitungan hiposenter.

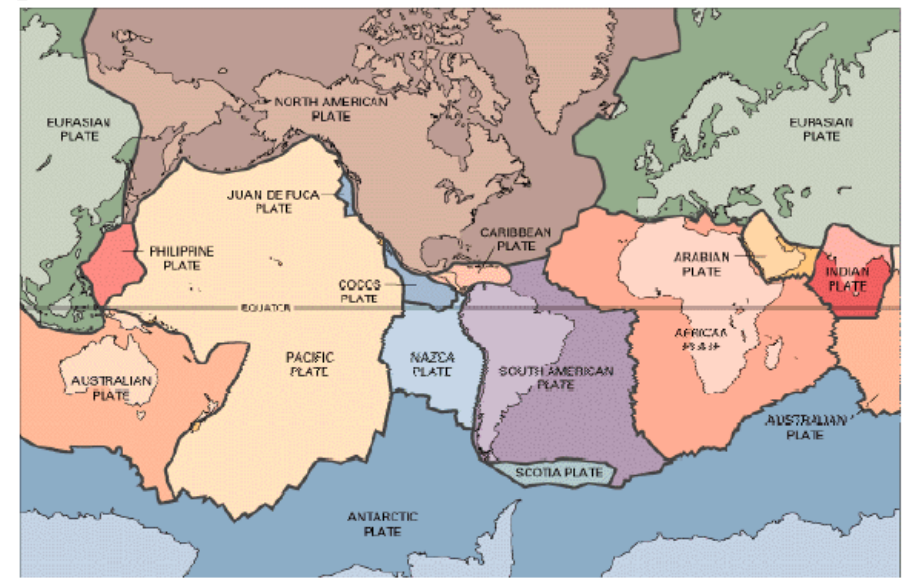

Gambar 1. Tectonic Setting (Kious and Tilling dalam [1] )

Berbagai metode telah dilakukan untuk mempercepat proses penentuan waktu tiba gelombang $\mathrm{P}$ dan $\mathrm{S}$ yaitu dengan metode manual dan metode automatic picking. metode manual dengan cara menghitung waktu tiba gelombang gempabumi, yaitu watku tiba gelombang $\mathrm{P}$ dan gelombang $\mathrm{S}$. Selisih kedua waktu ini dapat digunakan untuk menentukan lokasi gempa bumi. Metode lain yang digunakan adalah dengan aplikasi Fast Fourier Transform (FFT) dalam bentuk spektogram. Penentuan waktu tiba gelombang secara manual mempunyai kelemahan yaitu lama dalam penentuan fase gelombang $\mathrm{P}$ dan $\mathrm{S}$ serta kadang terjadi kurang akurat dalam pembacaan waktu tiba gelombangnya, sedangkan untuk automatic picking dengan FFT ini dapat mempercepat proses penentuan fase gelombang gempabumi.

\section{METODE PENELITIAN}

Sinyal seismik pada dasarnya adalah gelombang yang diradiasikan dari sumber seismik, baik yang berupa buatan (aktivitas manusia) maupun yang alami seperti gempa akibat patahan, subduksi maupun runtuhan. Sinyal seismik sesungguhnya menggambarkan pergerakan batuan/medium dalam fungsi waktu atau kecepatan dengan durasi waktu tertentu [2].

Ketika suatu patahan bergerak dan menimbulkan gempa bumi, maka getarannya akan dicatat dalam seismograf sebagai salah satu respon dari peristiwa tersebut (Gambar 2). Spektogram merupakan suatu gambaran bagaimana perubahan frekuensi terhadap waktu yang direpresentasikan dalam warna tertentu. Spektogram dihitung dengan membagi sinyal seismik ke dalam beberapa fungsi jendela yang kemudian diubah ke dalam domain frekuensi [1]. Untuk mendapatkan dilakukan teknik FFT pada tiap fungsi jendela tersebut. FFT sendiri merupakan pengembangan dari Fourier Transform (FT). FT mendekomposisi sinyal seismik menjadi domain frekuensi yang sesunggguhnya menggambarkan bagaimana energi dari peristiwa gempa bumi itu terdistribusi pada medium yang dilewatinya [3].

FT didefinisikan sebagai berikut :

$$
F(\omega)=\int_{-\sim}^{\sim} f(x) e^{-i \omega x} d x
$$


dimana FT biasanya diselesaikan dalam bentuk bilangan kompleks untuk lebih menyederhanakan fungsi gelombang yang diasumsikan bersifat sinusoidal.

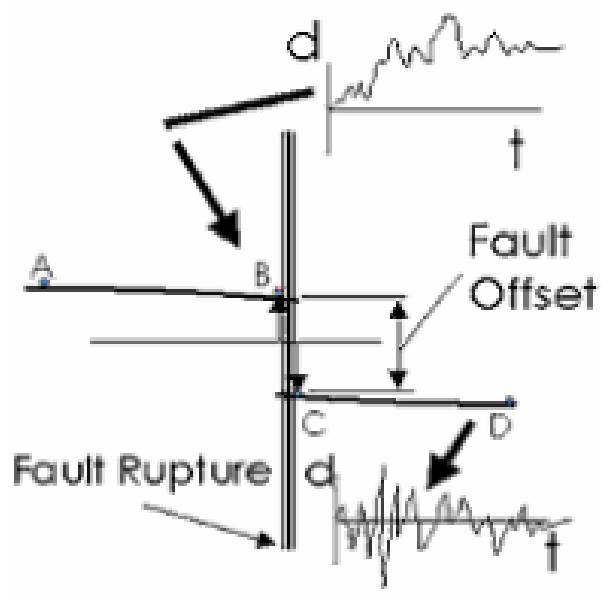

Gambar 2. Seismogram sebagai respon (visualisasi) dari peristiwa gempa bumi [1]

FT dalam jumlah yang besar biasanya dilakukan dengan cara numerik sehingga selanjutnya perhitungannya disebut dengan Discrete Fourier Transform (DFT). Sedikit berbeda dengan Persamaan 1, DFT dirumuskan dalam Persamaan 2 sebagai berikut:

$$
A_{k}=\sum_{n=0}^{N-1} e^{-i \frac{2 \pi}{N} k n} a_{n}
$$

Sedangkan FFT sendiri merupakan perhitungan cepat dari DFT dengan jumlah perhitungan sebanyak $2 N \log _{2} N$ dengan $N$ adalah jumlah data [4]. FT memiliki banyak kegunaan, salah satunya adalah dapat menentukan posisi dari frekuensi maksimum dari semuah sinyal yang sifatnya unik tergantung pada karakteristik data [5]. FT tidak hanya dapat diaplikasikan pada gelombang $\mathrm{P}$ dan $\mathrm{S}$ (keduanya dikenal sebagai gelombang badan) untuk kebutuhan automatic picking, tetapi juga dapat diaplikasikan pada gelombang lainnya seperti gelombang Rayleigh dan gelombang Love atau yang biasa dikenal dengan sebutan gelombang permukaan. Analisa gelombang permukaan berguna untuk menentukan properti sebuah medium seperti soil, kecepatan gelombang geser, modulus geser, damping ratio, dan kedalaman soil itu sendiri. Penggunaan gelombang permukaan ini biasanya dalam studi kasus mikroseismik. Noise dalam fungsi waktu merupakan hal yang sangat rawan terjadi pada metode mikroseismik sehingga walaupun FT dapat dilakukan pada gelombang permukaan hasilnya menjadi kurang maksimal karena ketergantungannya terhadap fungsi waktu dan untuk menanggulanginya biasanya digunakan transformasi wavelet [5].

Diagram alir penelitian dapat ditunjukkan pada gambar 3 dibawah ini: 


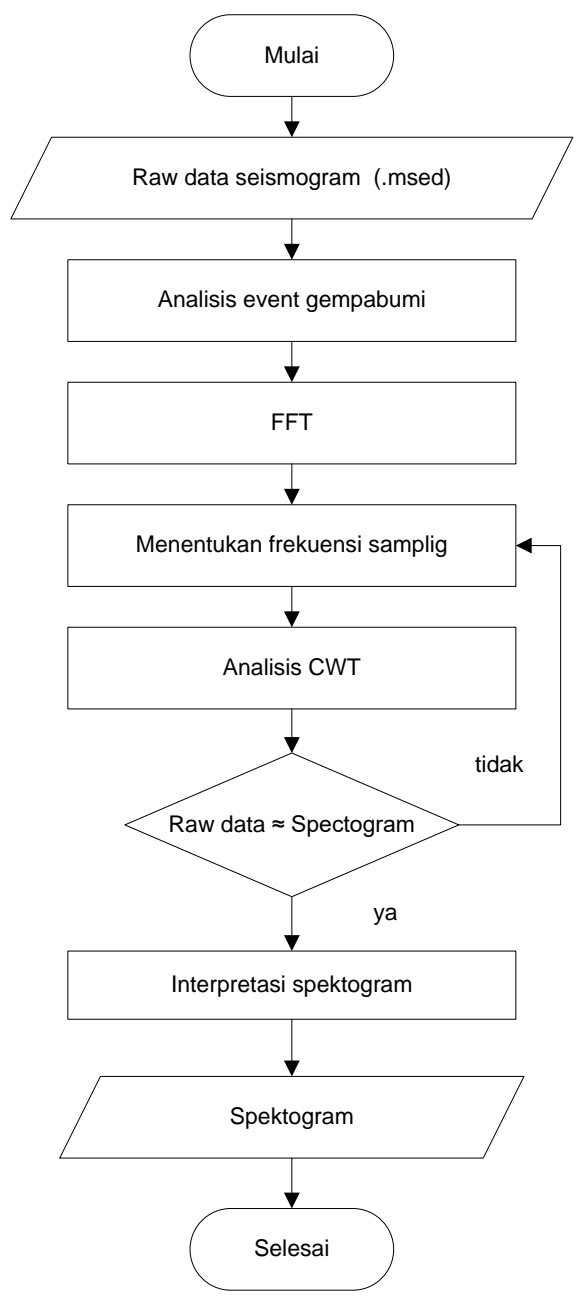

Gambar 3. Diagram alir penelitian

Pada penelitian kali ini, data yang digunakan adalah seismogram data beberapa gempa bumi yang terjadi di Indonesia dengan berbagai magnitudo yang telah diunduh dari website IRIS. Kemudian pada data tersebut dilakukan FFT sampai didapatkan profil spektogramnya dengan mengguanakan aplikasi Obspy pada Python. Python dipilih karena kemampuannya yang cepat dalam mengeksekusi data besar dan bahasa pemrogramannya yang mudah untuk dipahami. Pada python juga terdapat modul yang lengkap terutama dalam bidang data science.

\section{HASIL DAN PEMBAHASAN}

Salah satu contoh data gempa yang telah diunduh dari website IRIS (http://ds.iris.edu/ds/ akses 2 November 2019) adalah data gempa Lombok pada 5 Agustus 2018 (Gambar 4). Kemudian dilakukan analisa FFT untuk didapakan hasil spektogramnya seperti pada Gambar 5.

Berdasarkan Gambar 5 dapat diketahui bahwa waktu tiba gelombang $\mathrm{P}$ dan $\mathrm{S}$ ditandai dengan adanya penguatan warna spektrum pada seismogram (garis hitam). Gambaran spektogram ini mengindikasikan bahwa distribusi energi dari kedua gelombang badan tersebut memiliki nilai yang tinggi dibandingkan dengan gelombang gempa permukaan.

Hal ini senada dengan kondisi sebenarnya dimana gelombang $\mathrm{P}$ memiliki besaran kecepatan tertinggi diantara gelombang lainnya sehingga waktu yang dibutuhkan oleh gelombang tersebut untuk mencapai stasiun pencatat gempa relatif lebih cepat dibandingkan dengan gelombang gempa lainnya. Selain gempa Lombok pada tanggal 5 Agustus 2018, dilakukan juga perhitungan seismogram pada data gempa Lombok tanggal 28 Juli 2018 dan gempa Palu Koro 28 September 2018.

Berdasarkan Gambar 6 (a) yang merupakan gempa foreshock dari gempa Lombok pada 5 Agustus 2018, terlihat bahwa spektogram cenderung memiliki pola spektrum yang hampir sama, tidak ada pola sepktrum yang dominan seperti pada Gambar 5.

Hal ini a pada gempa tersebut, event gempa tidak terlihat dengan jelas. Sedangkan pada Gambar 6 (b) event gempa tergambarkan jelas namun sulit menentukan waktu tiba gelombang $\mathrm{P}$ dan $\mathrm{S}$ karena terdapatnya peristiwa tsunami sehingga memberikan respon yang cukup besar pada 
amplitudo seismogram yang pada akhirnya direspon pula pada seismogram dengan suatu spektrum yang cukup lebar dan homogen (lingkaran hitam).

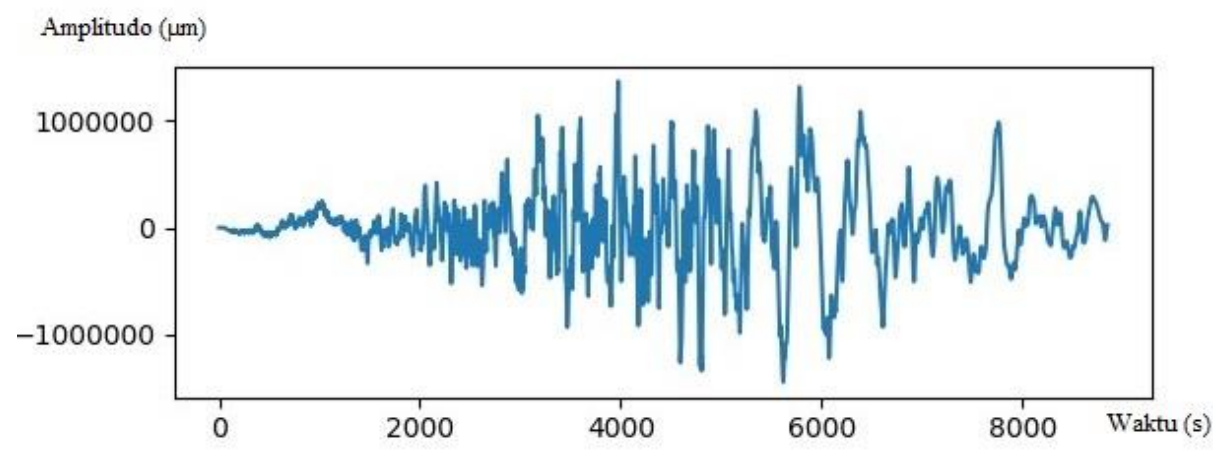

Gambar 4. Rekaman Gempa Lombok 2018

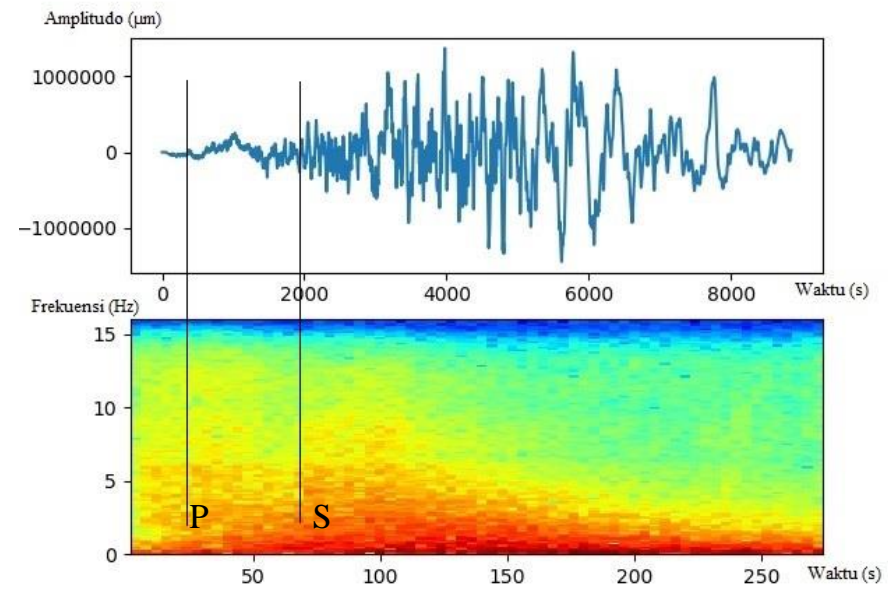

Gambar 5. Spektogram gempa Lombok 2018

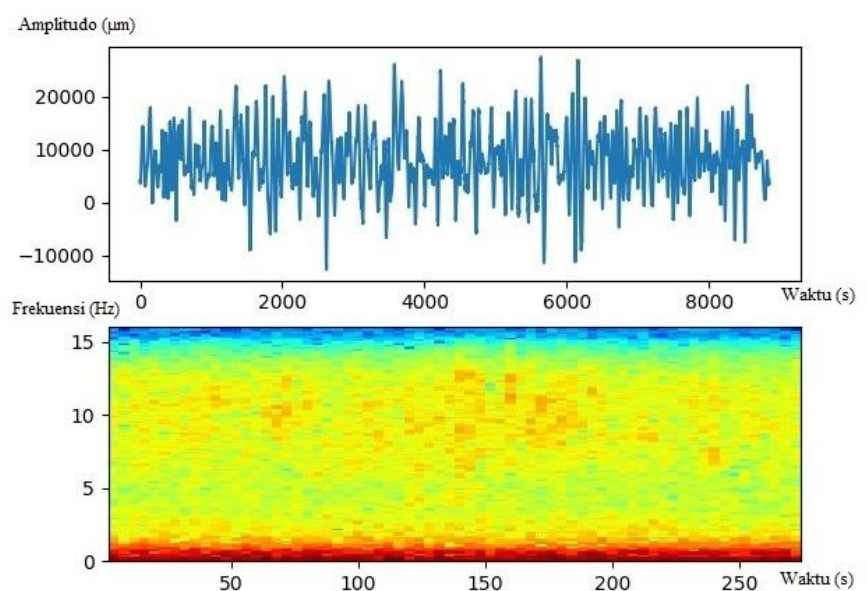

(a) 


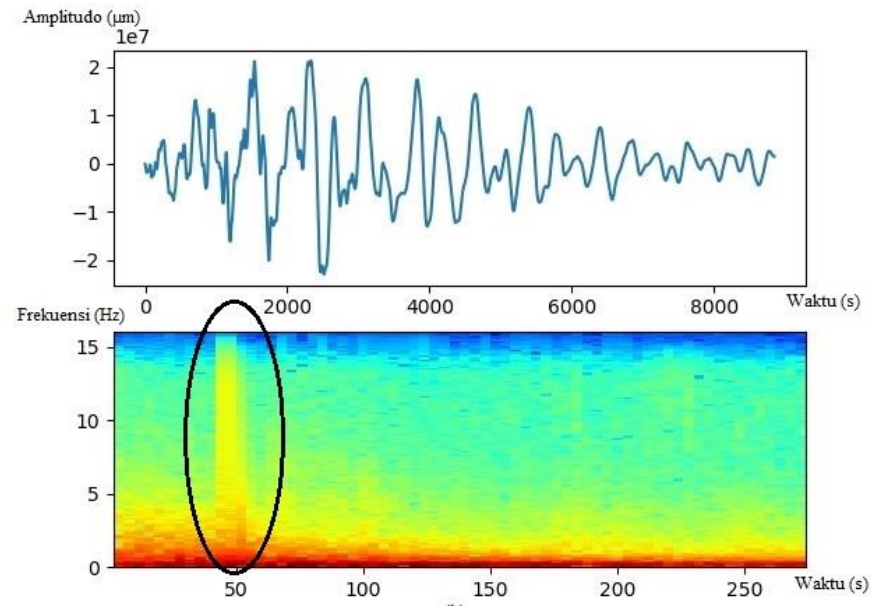

(b)

Gambar 6. (a) Spektogram gempa Lombok 28 Juli 2018; (b) Spektogram gempa Palu Koro 28 September 2018

\section{KESIMPULAN}

Berdasarkan hasil perhitungan spektogram pada beberapa data gempa diketahui bahwa spektogram dapat memetakan dengan jelas waktu tiba gelombang $\mathrm{P}$ dan $\mathrm{S}$ pada seismogram pada event gempa yang terekam dengan baik, seperti pada Gempa Lombok 5 Agustus 2018. Sedangkan pada gempa foreshock dari gempa Lombok pada 28 Juli 2018, spektogram tidak menunjukkan hasil yang maksimal karena perekaman seismogram yang kurang maksimal. Begitu pula dengan spektogram pada peristiwa tsunami di Palu Koro, spektogram menunjukkan respon yang tinggi sesuai dengan kuatnya amplitudo gempa yang disusul dengan tsunami tetapi kurang maksimal dalam menentukan waktu tiba gelombang $\mathrm{P}$ dan $\mathrm{S}$ nya.

\section{UCAPAN TERIMAKASIH}

Ucapan terimakasih penulis sampaikan kepada LPPM UPN Veteran Yogyakarta yang telah memberikan bantuan dana hibah penelitian dasar internal batch kedua tahun 2019.

\section{DAFTAR PUSTAKA}

[1] J. Hedberg, "Spectrogram Evaluation of Seismic Risk in Managua, Nicaragua," Engineering Geology. Lund University, Sweden, 2005.

[2] C. Huerta-Lopez and Y. Shin, "Time-frequency analysis of earthquake records," ... Earthq. ..., 2000.

[3] P. Heckbert, "Fourier Transforms and the Fast Fourier Transform (FFT) Algorithm," Notes Comput. Graph., 1995.

[4] L. E. Upegui-Botero, F.M.; HuertaLópez, C. I.; Caro-Cortes, J. A.; Martínez-Cruzado, J. A. ; SuarezColche, "Joint Time-Frequency Analysis of Seismic Records," Proc. 15 WCEE 2012, 2012.

[5] S. A. P. Rosyidi and M. Raihan, "Wavelet Spectrogram Analysis of Surface Wave Technique for Dynamic Soil Properties Measurement on Soft Marine Clay Site," in Seismic Waves - Research and Analysis, 2012. 
